\title{
Correspondence
}

\section{Safety check for the Bain Circuit}

To the Editor:

The Bain circuit was introduced by Bain and Spoerel ${ }^{1}$ in 1972 . Of major concem is the potential malfunctioning of the circuit due to avulsion of the inner fresh gas delivery tube at the machine end of the circuit. This will turn the outer tube into dead space. Hannallah ${ }^{2}$ described this hazard and recommended inspection of the inner tube before use of the circuit. Pethick ${ }^{3}$ described a procedure to check the circuit to detect the above problem. This procedure (oxygen flush test) consists of flushing the circuit with the oxygen "flush valve" and observing the reservoir bag. Collapse of the reservoir bag, secondary to the Venturi effect in the outer tube, is an indication that the circuit is intact. A description of this test is included in the package insert of the Bain circuit. However this test is not foolproof. Peterson ${ }^{4}$ described a situation in which the Pethick test failed to expose a faulty Bain circuit in which the inner tube was missing.

I would like to suggest another method to check the Bain circuit for disconnection of the inner tube:

The circuit is connected to the Bain adaptor. The reservoir bag and the fresh gas flow tube are connected to the circuit. The elbow, at the patient's end, is removed. Oxygen is turned on at $2 L /$ minute. The end of the inner tube (at the patient end of the circuit) is oceluded, with the tip of a plunger from a $3 \mathrm{ml}$ syringe, for $2-3$ seconds. When the plunger is removed, a very obvious "hissing sound" is heard. This is caused by the sudden release of $\mathrm{O}_{2}$ which accumulated in the inner tube of the circuit. Another sign of the integrity of the circuit is that when the inner tube is occluded, the $\mathrm{O}_{2}$ rotameter descends slightly. Once the occlusion is relieved, the rotameter will ascend to its original position. Failure to elicit these signs indicates that there is no fresh gas flow at the patient end of the inner tube. The cause of this absent flow must be sought. If oxygen flows through the fresh gas out flow, from the machine to the circuit and at the same time the described signs are not elicited, then the inner tube of the Bain circuit is either broken or disconnected. The circuit must not be used.

In 1977, Foex and Crampton Smith ${ }^{5}$ described a similar test. It consists of occluding the distal (patient) end of the Bain circuit with the index finger, thus occluding the end of the inner tube, and observing the rotameter descend, followed by recovery of its original position once the finger is withdrawn. One fault of this maneuver is that, because of the design of the patient end of the Bain circuit, unless one has an extremely slender finger: it is impossible to occlude the distal end of the inner tube without occluding the outer tube. In the same communication the author stated that Goat suggested the use of a plunger of a $2 \mathrm{ml}$ syringe, instead of the finger, for hygenic reasons.

The basic principle of the Foex-Crampton Smith Manoeuver and the test described by this communication is to have only the inner tube occluded, without occluding the outer tube

If either test is done while the outer tube is partially or completely occluded, the above mentioned signs could be elicited even if the inner tube is avulsed or disconnected. This is more likely to happen if the reservoir bag is already full and the "pop-off valve" is closed.

In performing this test, a low flow of $\mathrm{O}_{2}$ should be used and the inner tube should be occluded for a short time ( $2-3$ seconds). Using very high flows or prolonged occlusion will cause high pressure to build up in the system. This, in turn, may blow off the inner tube or cause damage to the anaesthetic machine. 6

Ghaleb A. Ghani мв в CH

Department of Anesthesiology

Emory University School of Medicine

Emory University Hospital

Atlanta, Georgia

REFERENCES

I Bain JA, Spoerel WE. A streamlined anaesthetic system. Can Anaesth Soc J 1972; 19: 426. 
2 Hannallah $R$, Rosales $J K$. A hazard connected with re-use of the Bain's circuit: A case report. Can Anaesth Soc J 1974, 21 : 511-3.

3 Pethick SL. Letter to the editor. Can Anaesth Soc J 1975, 22: 115

4 Peterson WC. Bain circuit. Can Anaesth Soc J 1978, 25: 532 .

5 Foex $P$, Crampion Smith A. The Foex-Crampton Smith Manneuvre. Anaesthesia, 1977, 32: 294.

6 Sall R. A test for co-axial circuits: A waming and a suggestion, Anaesthesia 1977, 32:675.

\section{$\operatorname{COMMENT}$}

Thank you for the opporiunity to reply to Dr. Ghani's letter. The test Dr. Ghani describes points out again how important it is to check breathing circuits for proper function before each use.

I routinely visually inspect each circuit to assure that the biue inner tube does extend from the patient end connector to protrude slightly outside the circuit at the fresh gas connecting nipple. I then personally connect the circuit to the gas machine and perform the Pethick test and finally pressurize the circuit to $30 \mathrm{~cm}$ of water pressure for a few seconds to assure there are no significant leaks. This routine testing takes about 20 seconds. Perhaps now I will include the Ghani test and the Foex-Crampton Smith manoeuvre. Both tests are easily performed and give further assurance the inner tube of a Bain Breathing Circuit is intact. The FoexCrampton Smith manoeuvre also nicely checks the integrity of the hard circuitry of the gas machine from the connecrion at the fresh gas nipple of the circuit back to the rotameters. I would encourage all readers to look up the original publication on the Foex-Crampton Smith manoeuver, as it makes delightul reading!

The inner tube of the Bain Breathing Circuit is recessed at the patient end thus necessitating the use of a plunger from a 2 or $3 \mathrm{~m} /$ syringe to carry out the Ghani test or the Foex-Crampton Smith manoeuvre. The inner tube is recessed to prevent obstruction to exhalation by the elbow connector or the endotracheal tube connector. The minimal dead space is of no consequence even to the premature baby.

Finally I would like to emphasize that everyone must routinely carry out safety checks of any anaesthesia circuit before each use to assure its proper function.

James A. Bain MD FRCP(C)

Department of Anaesthesia

Victoria Hospital

London, Ontario

Bain Breathing Circuit, Registered Trademark of the Kendall Company, Boston, Massachusetts.

REFERENCES

1 Pethick SL. Letter to the Editor, Can Anaesth Soc J 1975 ; 22: 115.

2 Foex-Crampton Smith A. The Foex-Crampton Smith Manoeuvre, Anaesthesia, 1977; 32: 294.

\section{Oxygen monitoring of bleomycin-treated patients}

To the Editor:

Oxom, et al., ${ }^{1}$ discussed an important aspect in the anaesthetic management of the surgical patient previously treated with bleomycin. Although our experience with these patients undergoing thoracotomy ${ }^{2}$ suggests that they do tolerate higher $\mathrm{FiO}_{2}$ 's than previously recognized ${ }^{3}$ like Oxorn et al., it is still our practice to administer the lowest concentration of oxygen compatable with safe levels of arterial oxygenation.

Oxorn et al. described their experience with an indwelling in vivo arterial oxygen tension monitoring system. They detailed the potential hazards of intra-arterial cannulation as well as the very real shortcomings of other methods of oxygen monitoring. Their article failed to mention an accurate, non-invasive oxygen monitor that is currently available. We now use a pulse-oximeter (Nellcor, Hayward, CA) for continuous monitoring of oxygenation on our high risk patients. Unlike the less dependable ear oximeters, the Nellcor device uses a sensor that is easily wrapped around any pulsating artery. For convenience we use a finger. The monitor digitally displays arterial hemoglobinoxygen saturation $\left(\mathrm{SaO}_{2}\right)$, and is extremely accurate over a wide range of hemodynamic conditions. ${ }^{4}$ For bleomycin-treated patients, we use the lowest "safe" amount of supplemental oxygen as determined by reducing the $\mathrm{FIO}_{2}$ until an $\mathrm{SaO}_{2}$ of 90-95 per cent is reached. Non-invasive finger pulse oximetry is an ideal means of continuously monitoring patients at risk for hypoxemia or for oxygen toxicity such as the bleomycin-treated patient described by Oxorn.

Jay B. Brodsky MD

Mark S. Shulman MD

Department of Anesthesia

Stanford University School of Medicine

Stanford, California

REFERENCES

1 Oxorn DC, Chung DC, Lam AM. Continuous in-

vivo monitoring of arterial oxygen tension in a patient treated with bleomycin. Can Anaesth Soc J $1984 ; 31: 200-5$ 